\title{
Effect of pre-incubation temperature on susceptibility of Galleria mellonella larvae to infection by Candida albicans
}

\author{
Peter Mowlds $\cdot$ Kevin Kavanagh
}

Received: 15 August 2007/Accepted: 19 September 2007/Published online: 6 October 2007

(C) Springer Science+Business Media B.V. 2007

\begin{abstract}
The use of insects for evaluating the virulence of microbial pathogens and for determining the efficacy of antimicrobial drugs is increasing. When larvae of the greater wax moth Galleria mellonella were incubated at 4 or $37^{\circ} \mathrm{C}$ for $24 \mathrm{~h}$. prior to infection, they manifested increased resistance to infection by the yeast Candida albicans compared to larvae that had been pre-incubated for $24 \mathrm{~h}$ at $30^{\circ} \mathrm{C}$. Incubation at 4 or $37^{\circ} \mathrm{C}$ led to an increase in haemocyte density and the expression of genes coding for gallerimycin, transferrin, an inducible metalloproteinase inhibitor (IMPI) and galiomicin. Peak expression of these genes was recorded at approximately $24 \mathrm{~h}$ after the commencement of the 4 or $37^{\circ} \mathrm{C}$ incubation. These results indicate that exposure of larvae to mild thermal shock conditions induces a protective cellular and humoral immune response mediated by increased numbers of haemocytes and elevated expression of antimicrobial peptides.
\end{abstract}

Keywords Anti microbial peptides .

Cellular response - Galleria mellonella .

Gene expression - Haemocytes · Host defence ·

Humoral response

P. Mowlds $\cdot$ K. Kavanagh $(\bowtie)$

Medical Mycology Unit, NICB, Department of Biology, National University of Ireland Maynooth, Maynooth,

Co. Kildare, Ireland

e-mail: kevin.kavanagh@nuim.ie

\author{
Abbreviations \\ AMP Anti-microbial peptide(s) \\ IMPI Inducible metalloproteinase inhibitor
}

\section{Introduction}

The insect immune system demonstrates a number of structural and functional similarities to the innate immune system of mammals [1] and, as a consequence, insects can be utilised as models for assessing the virulence of a variety of microbial pathogens [2,3]. A wide range of insects are now employed to assess microbial virulence or to determine the antimicrobial activity of drugs. Larvae of the greater wax moth Galleria mellonella have been shown to be an efficient model for studying the in vivo pathogenicity of yeasts [4], mutants of Candida albicans [5] and the virulence of Aspergillus fumigatus [6].

The immune response of insects consist of a cooperative functioning system with both humoral and cellular components. The cellular immune response consists of the rapid synthesis and moblilisation of immune cells called haemocytes, which engulf or surround invading pathogens. Six types of haemocytes have been classified [7] and include plasmatocytes, granulocytes, prohaemocytes, coagulocytes, spheruloctes and oenocytoids [8]. The humoral element of the insect immune response consists of the production of antimicrobial peptides 
(AMP) which are a primitive yet competent mechanism of defence found in vertebrates, insect and plants [9, 10]. AMPs are mostly small, less than $10 \mathrm{kDa}$ in size, and hydrophobic membrane active peptides. These peptides alter the cell membrane of pathogenic microorganisms and recognise the acidic phospholipids exposed on the surface of the bacterial membrane [11]. AMPs found in Galleria mellonella include inducible metalloproteinase inhibitor (IPMI), transferrin, galiomicin and gallerimycin and these play an important role in the insect humoral response [12]. Without the signal dependent synthesis of AMPs insects would succumb quickly to microbial infection [13]. It has been previously demonstrated that $G$. mellonella larvae pre-inoculated with a sublethal dose of the yeast Candida albicans or fungal cell wall components demonstrate an increased expression of the antimicrobial peptides and are capable of dealing with a potentially lethal doses of C. albicans [12].

The aim of the work presented here was to establish the effect of incubation temperature on the immune response of $G$. mellonella to infection by the yeast $C$. albicans. Incubation temperature can significantly affect insect physiology and behaviour [14] and it was hoped to establish how temperature altered the cellular and immune responses of G. mellonella larvae, so that optimal condition for the use of this insect in in vivo assays could be determined.

\section{Material and methods}

Chemicals

All Chemicals and reagents were of the highest quality and purity and unless otherwise stated were purchased from Sigma Aldrich Chemical Co. Ltd, Dorset, UK.

Yeast strains and culture conditions

The yeast strain used in this study was Candida albicans MEN (a generous gift from Dr. D. Kerridge, Cambridge, UK). Yeast cultures were grown to the stationary phase (approximately $1 \times 10^{8} / \mathrm{ml}$ ) in $50 \mathrm{ml}$ of YEPD broth (2\% (w/v) glucose, 2\% (w/v) bactopeptone (Oxoid Ltd., Basingstoke, England) and $1 \%(\mathrm{w} / \mathrm{v})$ yeast extract (Oxoid)) in $100 \mathrm{ml}$ conical flasks at $30^{\circ} \mathrm{C}$ and $200 \mathrm{rpm}$ in an orbital incubator.

Insect larvae

Sixth instar larvae of G. mellonella (Lepidoptera: Pyralidae, the Greater Wax Moth)(Mealworm Company, Sheffield, England) were stored in wood shavings in the dark at $15^{\circ} \mathrm{C}$ and larvae were inoculated as described previously [4]. Only larvae weighing between 0.2 and $0.4 \mathrm{~g}$ were used during this study.

Pre-incubation of insect larvae

Three thermal treatments were utilised in this work. All larvae were stored at $15^{\circ} \mathrm{C}$ initially but in the $24 \mathrm{~h}$ immediately prior to infection with $C$. albicans larvae were maintained at 4,37 or $30^{\circ} \mathrm{C}$ in the dark and then incubated, following inoculation, at $30^{\circ} \mathrm{C}$. Ten larvae were used per treatment and all experiments were performed on three independent occasions.

Determination of haemocyte density

Haemocyte density was assessed by bleeding three larvae into a pre-chilled microcentrifuge tube containing a few granules of phenylthiourea to prevent melanisation, as described [15]. Dilutions were made by mixing the haemolymph with $0.37 \%(\mathrm{v} / \mathrm{v})$ mercaptoethanol in sterile PBS. Haemocyte density was assessed with the aid of a Neubauer haemocytometer.

Analysis of expression of immune relevant proteins of $G$. mellonella by RT-PCR

A TRI-reagent method was used for the extraction of RNA from larvae incubated at 4,30 or $37^{\circ} \mathrm{C}$ for various periods of time. About $2 \mu \mathrm{g}$ of RNA was used for the synthesis of cDNA using a SuperScript Kit (Introvogen) with oligo (dT) primers. RNA was treated with DNase I prior to cDNA synthesis. Amplification of target genes was performed using 
primers that are previously described [12] and using the following cycle conditions: $98^{\circ} \mathrm{C}$ denaturation for $2 \min \left(94^{\circ} \mathrm{C}\right.$ denaturation for $60 \mathrm{~s}, 55^{\circ} \mathrm{C}$ for $60 \mathrm{~s}$, $72^{\circ} \mathrm{C}$ extension for $\left.90 \mathrm{~s}\right) \times 30$ cycles; $72^{\circ} \mathrm{C}$ extension for $10 \mathrm{~min}$. Amplified products were visualised on a 1\% Agarose gel containing ethidium bromide after which a Sygene Geneflash and densitometric analysis of PCR products was carried out using Imagequant software. All samples were normalised against $\beta$ actin values. The highest level of expression was set to $100 \%$ and other values are given as a percentage of relative activity [16].

\section{Statistical analysis}

All assays were preformed on three independent occasions. Results are expressed as the mean $\pm \mathrm{SE}$ and were compared by $t$-test using Sigma Stat Statistical analysis Package Version 1.00 (SPSS Inc, Chicago, IL, USA). Differences were considered significant at $P \leq 0.05$.

\section{Results}

Effect of pre-incubation temperature on larval survival following microbial challenge

It has been established, previously, that exposure of Galleria larvae to non-lethal doses of yeast or fungal cell wall constituents protects against lethal doses of C. albicans [12]. In the work presented here, we sought to establish, whether temperature influenced larval survival. Larvae of $G$. mellonella were incubated at 4,37 or $30^{\circ} \mathrm{C}$ for $24 \mathrm{~h}$, as described, and inoculated with $5 \times 10^{5} \mathrm{C}$. albicans cells per larva. All larvae were subsequently incubated at $30^{\circ} \mathrm{C}$ and viability was monitored over a $72 \mathrm{~h}$ period. Incubation at the different temperature for $24 \mathrm{~h}$ prior to infection did not adversely affect larval survival. The results (Fig. 1) indicate that in larvae pre-incubated at $30^{\circ} \mathrm{C}$ viability decreased to $23 \pm 3.3 \%$ after $24 \mathrm{~h}$ after infection and to $10 \pm 0 \%$ after $72 \mathrm{~h}$. In contrast, prior exposure of larvae to a temperature of $37^{\circ} \mathrm{C}$ or $4^{\circ} \mathrm{C}$ ensured that $73 \pm 5.7 \%$ and $83 \pm 12 \%$ of larvae, respectively, were still alive after $24 \mathrm{~h}$ and that larval survival following these treatments is approximately $50 \%$ at $72 \mathrm{~h}$.
Effect of incubation temperature on larval haemocyte density

Haemocytes are immune cells that constitute the cellular arm of the insect immune response to pathogens and elevated levels of haemocytes have been previously associated with a protective response against microbial infections $[15,17,18]$. In order to establish whether a change in circulating haemocyte density was responsible for the protective effect observed in larvae pre-incubated at different temperatures haemolymph samples were isolated the number of haemocytes enumerated. Larvae that had been pre-incubated at $30^{\circ} \mathrm{C}$ prior to infection (Fig. 2) showed a haemocyte density of $3.2 \times 10^{5} /$ larva at $24 \mathrm{~h}$. Exposure of larvae to a temperature of $4^{\circ} \mathrm{C}$ increased haemocyte density to approximately $5.4 \times 10^{5}$ haemocytes/larva at 24 and $48 \mathrm{~h}$. Exposure of larvae to $37^{\circ} \mathrm{C}$ resulted in a dramatic increase in haemocyte density which reached $9.5 \times 10^{5} /$ larva after $24 \mathrm{~h}$ and $8.7 \times 10^{5} /$ larva after $48 \mathrm{~h}$. These results indicate that incubation temperature can induce an increase in haemocyte density that could contribute to the protective effective evident following $C$. albicans challenge.

Gene expression of proteins involved in an immune response

It has been previously established that exposure of Galleria larvae to a non-lethal dose of $C$. albicans, Saccharomyces cerevisiae or fungal cell wall constituents protects larvae against a subsequent lethal inoculation of $C$. albicans cells and that this protection is mediated by the increased expression of selected antimicrobial peptides [12]. The expression of selected immune proteins has also been shown to be increased in Drosophila during an immune response [16].

The expression of genes coding for selected antimicrobial peptides was examined in order to establish whether incubation temperature affected their expression in larvae. Larvae were exposed to the different temperature regimes, as described, and the gene expression of four AMPs was monitored at 1, 4, 18, 24 and $48 \mathrm{~h}$ (Fig. 3). It should be noted that inoculation normally occurred after the $24 \mathrm{~h}$ of incubation at the three test temperature. The genes 
Fig. 1 Viability of Galleria larvae inoculated with $C$. albicans following different thermal treatments. Larvae were pre-incubated 4,30 or $37^{\circ} \mathrm{C}$ for $24 \mathrm{~h}$ prior to infection with $C$. albicans. Infected larvae were subsequently incubated at $30^{\circ} \mathrm{C}$. The percentage survival at 0,24 , 48 and $72 \mathrm{~h}$ is recorded and all values represent the mean \pm standard error from three independent experiments

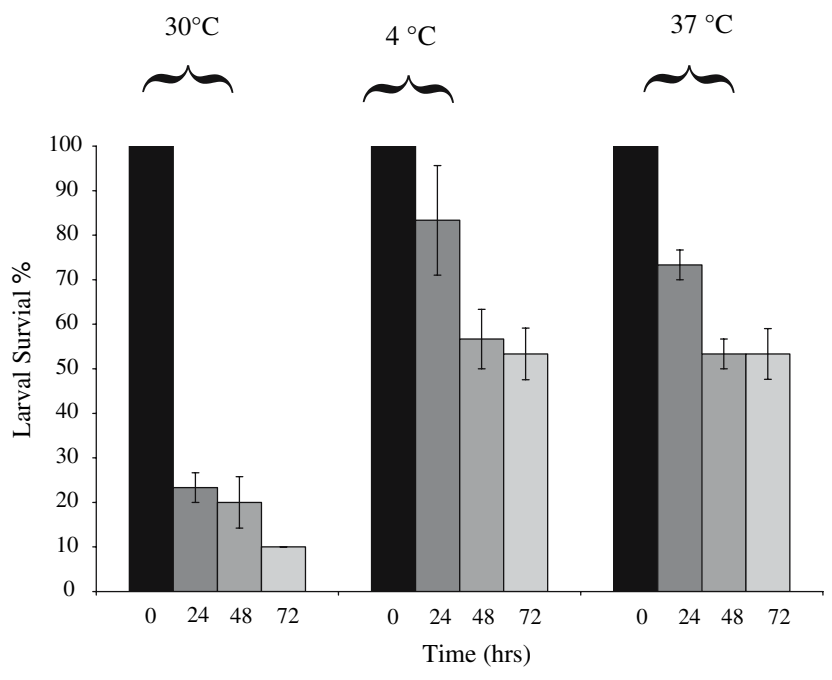

Fig. 2 The effect of incubation temperature on the haemocyte density of Galleria larvae.

Haemolymph was bled from insects that were incubated at 4,30 or $37^{\circ} \mathrm{C}$ and the density of haemocytes per larva was calculated. All values represent the mean \pm standard error from three independent experiments

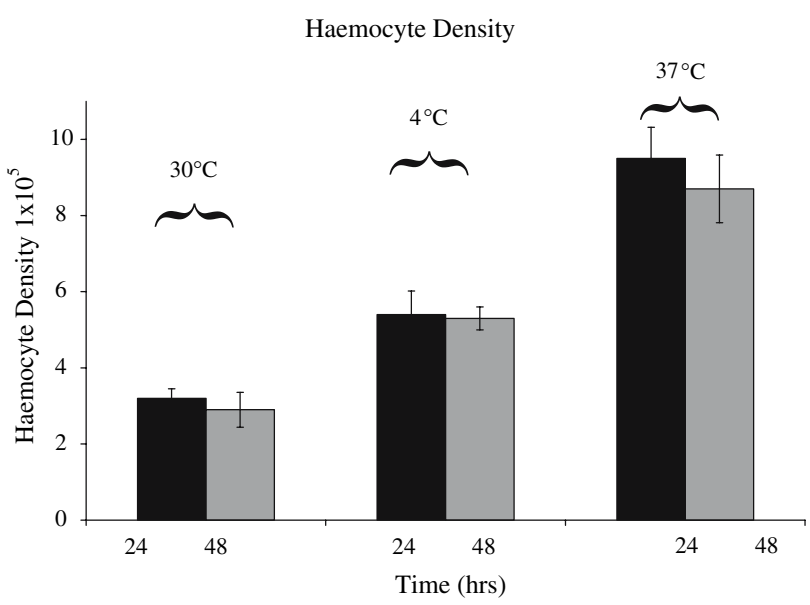

approximately twice those recorded at $0 \mathrm{~h}$ for larvae pre-exposed to $4^{\circ} \mathrm{C}$. The highest expression levels of gallerimycin for the different treatments were recorded at 24 h. (Fig. 4).

There was a small increase in expression of IMPI gene following incubation of larvae at $37^{\circ} \mathrm{C}$ and a dramatic drop at $48 \mathrm{~h}$. In the case of larvae preexposed to $4^{\circ} \mathrm{C}$ expression increases until $24 \mathrm{~h}$ and then declines. Larvae pre-exposed to $30^{\circ} \mathrm{C}$ increased expression but this increase is not as dramatic as following the other treatments (Fig. 4). Transferrin expression in all larvae is greatest at $24 \mathrm{~h}$ (Fig. 4) and initial levels in the three treatment regimes are similar but the elevation is greatest in those larvae preexposed to 4 or $37^{\circ} \mathrm{C}$.

The results presented here indicate that exposure of larvae to thermal stress, by incubation at 4 or $37^{\circ} \mathrm{C}$, 
Fig. 3 RT-PCR analysis of G. mellonella cDNA from whole larvae on a $1 \%$ agarose gel. Larvae were incubated at 4,30 or $37^{\circ} \mathrm{C}$ for various periods of time. PCR was performed using primers for galiomicin, gallerimycin, transferrin, IMPI and $\beta$ actin (housekeeping gene) on cDNA

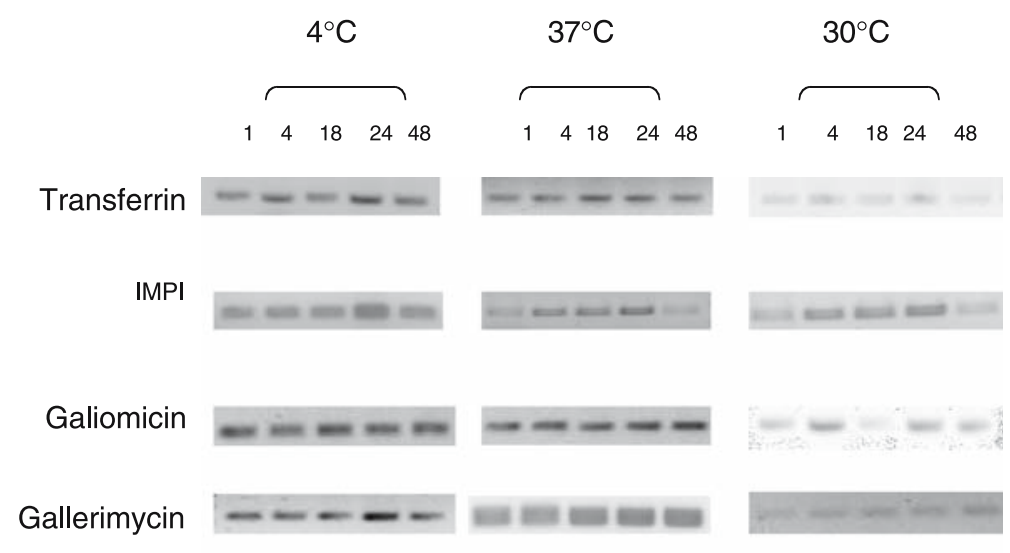

B Actin

induces increased expression of genes coding for key anti-microbial peptides and that in many cases peak expression is at $24 \mathrm{~h}$ which coincides with the administration of the potentially lethal C. albicans inoculation.

\section{Discussion}

There is an increasing awareness of the structural and functional similarities of the insect immune system and the innate immune system of mammals. Since the innate immune system of mammals represents the key response to microbial pathogens results obtained using insects can correlate with equivalent mammalian responses [5, 24]. This fact has been exploited through the use of insects for evaluating the virulence of microbial pathogens and for determining the efficacy of antimicrobial drugs prior to testing in mammals [2,3]. A wide variety of insects are now employed as models for in vivo pathogenicity testing and have been used for assessing the virulence of yeast [4], mutants of C. albicans [5], Cryptococcus neoformans [25], A. fumigatus [6] and in testing antimicrobial drugs [26]. We have previously demonstrated the increased survival of larvae of G. mellonella to infection by C. albicans by first exposing larvae to non-lethal levels of yeast or fungal cell wall constituents [12].

The work presented here indicates that exposure of larvae to different incubation temperatures prior to inoculation with $C$. albicans can significantly affect the insect immune response. Prior exposure of larvae to temperatures of 4 or $37^{\circ} \mathrm{C}$ increased survival following infection with $C$. albicans and this appears to be mediated by an elevation in the haemocyte density and in the expression of a number of antimicrobial peptides. Increased haemocytes density has been previously associated with protection of larvae from microbial pathogens $[15,17,18]$. In general, low haemocyte numbers equate with low survival rates (larvae that had been pre-incubated at $30^{\circ} \mathrm{C}$ for $24 \mathrm{~h}$ showed $3.2 \times 10^{5}$ haemocytes/larva and a survival rate of $23.3 \pm 3.3 \%$ ), while high haemocyte numbers occurred with high survival rates (larvae that had been pre-incubated at $4^{\circ} \mathrm{C}$ had a haemocyte density of $5.4 \times 10^{5} /$ larva of and a survival rate of $83 \pm 12 \%$ ) although this effect should not be seen in isolation as higher haemocyte numbers were observed in the larvae pre-incubated at $37^{\circ} \mathrm{C}$ but gave a lower survival rate $(73.5 \pm 5.7)$ to that seen in those larvae incubated at $4^{\circ} \mathrm{C}$. It should be noted (Fig. 4) that the greatest expression of antimicrobial peptides was recorded in larvae pre-incubate at $4^{\circ} \mathrm{C}$ and this together with the elevated haemocyte density is probably affecting larval survival.

Anti-microbial peptide production is part of the humoral component of the insect immune response and the main sites of synthesis of anti-microbial peptides in the insect are the fat body, haemocytes, the digestive tract, salivary glands and the reproductive tract. Anti-microbial peptides represent the last line of defence and are released into the haemolymph where they attack elements of the bacterial or fungal 
Galiomicin

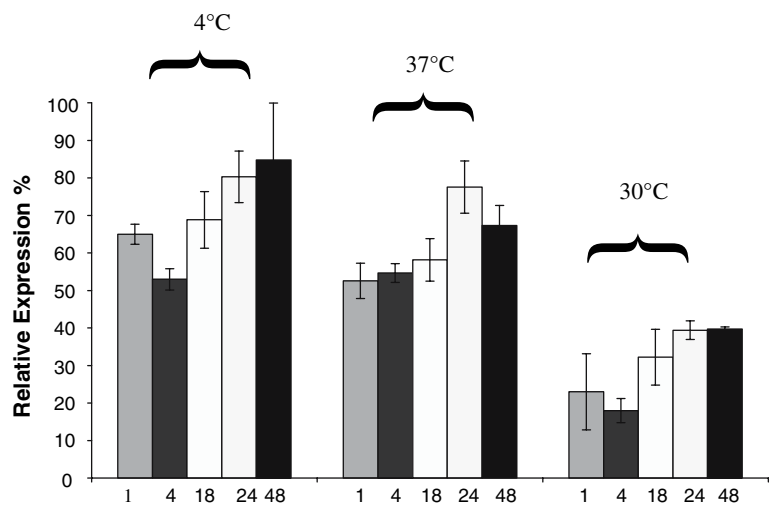

Gallerimycin

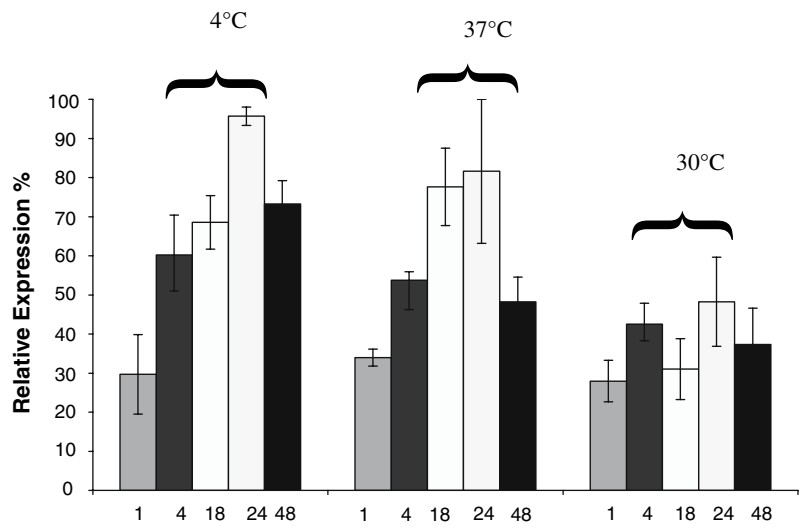

Fig. 4 Quantification of RT-PCR from larvae incubated at 4, 30 or $37^{\circ} \mathrm{C}$. Densitometric quantification of PCR products from unsaturated images of RT-PCR was performed using Genetools software (Syngene). Values were then normalised with the

cell wall [27]. Anti-microbial peptides are synthesised as pre-proproteins at a rate up to 100 times faster than IgM in mammals [28] and their small size allows diffusion through the haemolymph to counteract invading pathogens. Such peptides play a crucial role in combating infection and similar classes of peptides are found in vertebrates, invertebrates, and plants [29].

Analysis of the expression of genes coding for selected antimicrobial peptides revealed that incubation temperature significantly affects expression and that in many cases peak expression was evident at $24 \mathrm{~h}$, which coincided with the time larvae, were challenged with $C$. albicans. Galiomicin demonstrates antibacterial and antifungal effects [19] and increased expression has been recorded in $G$. mellonella larvae inoculated with $E$. coli. In the work presented here
IMPI

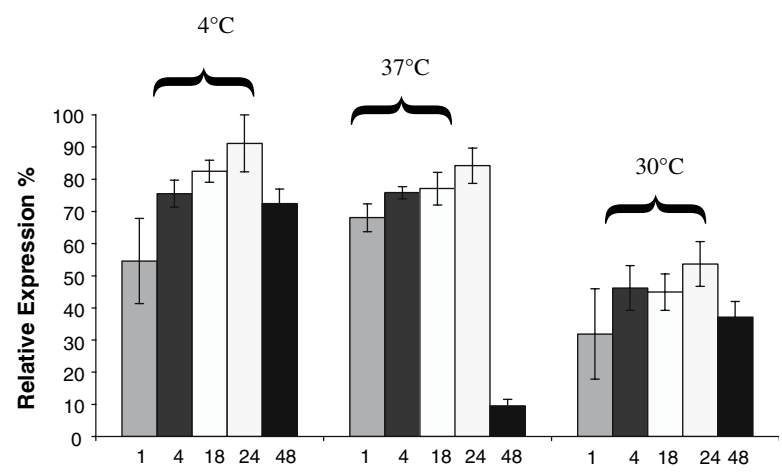

Transferrin

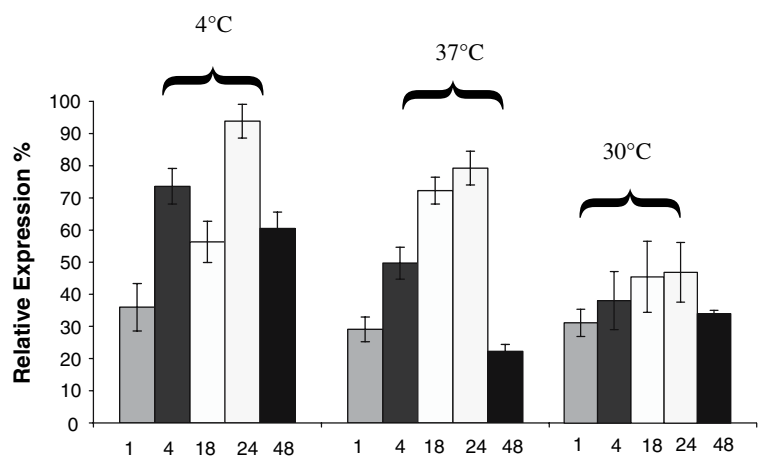

corresponding value of $\beta$ actin. The treatment that gave the highest level of expression was normalised to 100 and the remaining results are expressed as relative expression (\%)

galiomicin expression peaks at $24-48 \mathrm{~h}$ for those larvae pre-exposed to $4^{\circ} \mathrm{C}$ and at $24 \mathrm{~h}$ for those preincubated at $37^{\circ} \mathrm{C}$. Gallerimycin is a cysteine rich antimicrobial peptide and expression increases when larvae are inoculated with LPS [20]. Elevated expression levels of gallerimycin were recorded at all time points and peak expression was evident at $24 \mathrm{~h}$ in the three treatment groups. In insects transferrin has an iron-binding domain in the $\mathrm{N}$-terminal region and may function by sequestering iron from pathogens thus inhibiting their growth [21]. Transferrin expression in D. melanogaster is up regulated upon infection with bacteria [21]. In the work presented here transferrin expression levels show a dramatic increase in those larvae pre-incubated at 4 and $37^{\circ} \mathrm{C}$ while levels show a smaller increase in those larvae pre-incubated at $30^{\circ} \mathrm{C}$. Inducible metalloproteinase inhibitor (IMPI) was the 
first metalloproteinase inhibitor characterised in invertebrates and was purified from G. mellonella. IMPI has well-established antifungal properties [22] and acts by inhibiting the action of enzymes secreted by pathogenic microbes [23]. Peak expression levels of IMPI are achieved at $24 \mathrm{~h}$ in larvae subjected to the three temperature treatments.

The data presented here indicate that incubation temperature has a very strong effect on the immune response of G. mellonella larvae. Exposure of larvae to 4 or $37^{\circ} \mathrm{C}$ leads to increased survival following challenge with $C$. albicans and this protective response appears to be mediated by increased numbers of circulating haemocytes and by the elevated expression of genes coding for a range of antimicrobial peptides. Overall, pre-incubation of larvae at 4 or $37^{\circ} \mathrm{C}$ leads to greater levels of expression of antimicrobial peptides than pre-incubation at $30^{\circ} \mathrm{C}$ possibly indicating that the insect finds the higher $\left(37^{\circ} \mathrm{C}\right)$ and lower $\left(4^{\circ} \mathrm{C}\right)$ temperatures stressful [30]. Given the increased use of insects as models for in vivo testing of microbial pathogens and evaluation of antimicrobial drugs [2, 3] these findings indicate that the incubation temperature can significantly affect the larval immune response and thus fluctuations should be minimised to ensure consistency of results.

Acknowledgements This work was supported by funding from the Higher Education Authority of Ireland through the Programme for Research in Third Level Institutes III (20022007).

\section{References}

1. Vilmos P, Kurucz E. Insect immunity: evolutionary roots of the mammalian innate immune system. Immunol Lett 1998;62:59-66.

2. Kavanagh K, Reeves EP. Expoliting the potential of insects for the in vivo pathogenicity testing of microbial pathogens. FEMS Microbiol Rev 2004;28:101-12.

3. Scully LR, Bidochka M. Developing insect models for the study of current and emerging human pathogens. FEMS Microbiol Lett 2006;263:1-9.

4. Cotter G, Doyle S, Kavanagh K. Development of an insect model for the in vivo pathogenicity testing of yeasts. FEMS Immun Med Microbiol 2000;27:163-9.

5. Brennan M, Thomas DY, Whiteway M, Kavanagh K. Correlation between virulence of Candida albicans mutants in mice and Galleria mellonella larvae FEMS Immunol Med Microbiol 2002;34(2):153-7.
6. Reeves EP, Messina CGM, Doyle S, Kavanagh K. Correlation of gliotoxin production and virulence of aspergillus fumigatus in Galleria mellonella. Mycopathologia 2004; 158:73-9.

7. Boman HG, Hultmark D. Cell-free immunity in insects. Annu Rev Microbiol 1987;41:103-26.

8. Price CD, Ratcliffe NA. A reappraisal of insect haemocyte classification by the examination of blood from fifteen insect orders. Z Zellforsch Mikrosk Anat 1974;147:53749.

9. Lehrer RI, Lichtenstein AK, Ganz T. Defensins: antimicrobial and cytotoxic peptides of mammalian cells. Annu Rev Immunol 1993;11:105-28.

10. Lehrer RI, Ganz T. Antimicrobial peptides in mammalian and insect host defense. Curr Opin Immunol 1999;11:23-7.

11. Tytler EM, Anantharamaiah GM, Walker DE, Mishra VK, Palgunachari MN, Segrest JP. Molecular basis for prokaryotic specificity of magainin induced lysis. Biochemistry 1995;34:4393-401.

12. Bergin D, Murphy L, Keenan J, Clynes M, Kavanagh K. Pre-exposure to yeast protects larvae of Galleria mellonella from a subsequent lethal infection by Candida albicans and is mediated by the increased expression of antimicrobial peptides. Microbes Infect 2006;8:2105-12.

13. Bethencort R, Asha H, Dearolf C, Tony Y. Hemolymphdependent and independent responses in drosophila immune tissue. J Cell Biochem 2004;92:849-63.

14. Loetti MV, Burroni NE, Schweigmann N, de Garin A. Effect of thermal conditions on the pre-imaginal biology of Culex apicinus (Phillipi, 1865) (Diptera: Culicidae). J Vector Ecol 2007;32:106-11.

15. Bergin D, Brennan M, Kavanagh K. Fluctuations in haemocyte density and microbial load may be used as indicators of fungal pathogenicity in larvae of Galleria mellonella. Microbes Infect 2003;5(15):1389-95.

16. Lemaitre B, Reichhart JM, Hoffmann JA. Drosophila host defense: differential induction of antimicrobial peptide genes after infection by various classes of microorganisms. Proc Natl Acad Sci U S A 1997;94(26):14614-9.

17. Matha V, Mracek Z. Changes in haemocyte counts in Galleria mellonella (L) (Lepidoptera: Galleriidae) larvae infected with Steinernema sp. (Nematoda: steinernematidae). Nematol 1984;30:86-9.

18. Morton D, Dunphy G, Chadwick J. Reactions of haemocytes of immune and non-immune Galleria mellonella larvae to Proteus mirabilis. Develop Comparat Immunol 1987;11:47-55.

19. Lee YS, Yun EK, Jang WS, Kim I, Lee JH, Park SY, Ryu KS, Seo SJ, Kim CH, Lee IH. Purification, cDNA cloning and expression of an insect defensin from the great wax moth, Galleria mellonella. Insect Mol Biol 2004;13(1):65-72.

20. Schuhmann B, Seitz V, Vilcinskas A, Podsiadlowski L. Cloning and expression of gallerimycin, an antifungal peptide expressed in immune response of greater wax moth larvae, Galleria mellonella. Arch Insect Biochem Physiol 2003;53(3):125-33.

21. Yoshiga T, Georgieva T, Dunkov BC, Harizanova N, Ralchev K, Law JH. Drosophila melanogaster transferrin. Cloning, deduced protein sequence, expression during the 
life cycle, gene localization and up-regulation on bacterial infection. Eur J Biochem 1999;260(2):414-20.

22. Wedde M, Weise C, Kopacek P, Franke P, Vilcinskas A. Purification and characterization of an inducible metalloprotease inhibitor from the hemolymph of greater wax moth larvae, Galleria mellonella. Eur J Biochem 1998;255 (3):535-43.

23. Clermont A, Wedde M, Seitz V, Podsiadlowski L, Lenze D, Hummel M, Vilcinskas A. Cloning and expression of an inhibitor of microbial metalloproteinases from insects contributing to innate immunity. Biochem J 2004;382(1): 315-22.

24. Jander G, Rahme L, Ausbel F. Positive correlation between virulence of Pseudomonas aeruginosa mutants in mice and insects. J Bacteriol 2000;182:3843-5.

25. Mylonakis E, Moreno R, El Kohoury J, Idnurm A, Heitmann S, Calderwood S, Ausbel F, Diener A. Galleria mellonella as a model system to study Cryptococcus neoformans pathogenesis Infect. Immun 2005;73:3842-50.
26. Hamamoto H, Kurokawa K, Kaito C, Kamura K, Manitra Razanajatovo I, Kusuhara H, Santa T, Sekimizu K. Quantitative evaluation of the therapeutic effects of antibiotics using silkworms infected with human pathogenic microorganisms. Antimicrob Agent Chemother 2004;48: 774-9.

27. Ratcliffe N. Invertebrate immunity - a primer for the nonspecialist. Immunol Lett 1985;10:253-70.

28. Lowenberger C. Innate response of Aedes aegyptii. Insect Biochem Mol Biol 2001;31:219-29.

29. Salzet M. Vertebrate innate immunity resembles a mosaic of invertebrate immune responses. Trends Immunol 2001;22:285-8.

30. Wojda I, Jakubowicz T. Humoral immune response upon mild heat shock conditions in Galleria mellonella larvae. J. Insect Physiol 2007; (PMID 17631308). 